\title{
Recent trends in pre-monsoon daily temperature extremes over India
}

\author{
D R Kothawale*, J V Revadekar and K Rupa KumaR \\ Indian Institute of Tropical Meteorology, Pashan, Pune 411 008, India. \\ ${ }^{\dagger}$ Presently with World Meteorological Organization, Geneva, Switzerland. \\ *e-mail: kotha@tropmet.res.in
}

\begin{abstract}
Extreme climate and weather events are increasingly being recognized as key aspects of climate change. Pre-monsoon season (March-May) is the hottest part of the year over almost the entire South Asian region, in which hot weather extremes including heat waves are recurring natural hazards having serious societal impacts, particularly on human health. In the present paper, recent trends in extreme temperature events for the pre-monsoon season have been studied using daily data on maximum and minimum temperatures over a well-distributed network of 121 stations for the period 1970-2005. For this purpose, time series of extreme temperature events have been constructed for India as a whole and seven homogeneous regions, viz., Western Himalaya (WH), Northwest (NW), Northeast (NE), North Central (NC), East coast (EC), West coast (WC) and Interior Peninsula (IP).

In general, the frequency of occurrence of hot days and hot nights showed widespread increasing trend, while that of cold days and cold nights has shown widespread decreasing trend. The frequency of the occurrence of hot days is found to have significantly increased over EC, WC and IP, while that of cold days showed significant decreasing trend over WH and WC. The three regions EC, WC and NW showed significant increasing trend in the frequency of hot nights. For India as whole, the frequency of hot days and nights showed increasing trend while cold days and nights showed decreasing trends. Day-to-day fluctuations of pre-monsoon daily maximum and minimum temperatures have also been studied for the above regions. The results show that there is no significant change in day-to-day magnitude of fluctuations of pre-monsoon maximum and minimum temperatures. However, the results generally indicate that the daily maximum and minimum temperatures are becoming less variable within the season.
\end{abstract}

\section{Introduction}

Many studies have reported that the global as well as hemispheric mean surface air temperatures have significantly increased in the last century and pronounced warming has occurred in the last three decades (Jones et al 1999; Houghton et al 2001; Jones and Moberg 2003). On the regional scale, Kothawale and Rupa Kumar (2005) have examined trends in surface temperature over India for the period 1901-2003 and reported that the annual mean, maximum as well as minimum temperatures have significantly increased by $0.2^{\circ} \mathrm{C}$ per decade respectively during the last three decades, in a marked acceleration of the warming trend compared to the trends over the past century (1901-2003). However, manifestation of such changes on shorter timescale has been recognized to be one of the most crucial factors in terms of socio-economic impacts. Extremes in the temperature are characterised by daily temperature levels exceeding tolerable limits, and changes in their frequency, duration and amplitude are of great interest in impact assessment. For example,

Keywords. Climate change; pre-monsoon temperatures; climate extremes; heat waves. 
heat wave conditions are usually associated with fatal conditions, leading to sudden spurt in mortality. In May-June 2003, an unprecedented heat wave occurred in India, claiming an estimated 1600 lives (report on heat wave conditions in Andhra Pradesh, India 2004).

During the last two decades, more attention has been given to study the extremes in daily temperatures and their variability due to their adverse socio-economic impacts. However, studies of trends in temperature extremes and intra-seasonal variability of daily temperatures over various regions of the globe are still limited. Karl et al (1996) found significant decrease in days with extreme low temperature but no significant increase in the number of extreme warm temperature days over contiguous United States. Plummer et al (1999), using daily temperature data of Australia for the period 19611995, reported that there has been an increase in the frequency of warm days and nights and decrease in cool days and nights. Easterling et al (2000) reviewed briefly the observed variability and trends in extreme climate events over Australia, China and Central Europe, Northern Europe, New-Zealand and United States, and mentioned that frosty days decreased over these countries and days with warm maximum temperature were increased only over Australia and New-Zealand. Manton et al (2001) examined the trend in extreme daily temperature and rainfall for the period 19611998 for Southeast Asia and South Pacific and reported that annual number of hot days and warm nights significantly increased and annual number of cool days and cold nights significantly decreased. Arthur and Allen (2002) examined trends in the 20th century temperature extremes across United States, and found that the trends in annual occurrence of extreme maximum and minimum temperatures were strongly influenced by high exceedence counts during drought periods in the 1930s and 1950s. They also mentioned that the trends in the occurrence of extreme maximum and minimum temperatures were strongly influenced by urbanization. Hyun et al (2002) examined trends in extreme temperature events for the period 1954-1999 over South Korea and they observed that frequency of extreme maximum temperature events showed an increasing trend with higher values in 1980s and 1990s. Recently, Klein Tank et al (2006) studied the changes in daily temperature and precipitation extremes in central and south Asia, and found that $70 \%$ of the stations have statistically significant increases in the percentage of warm nights/days and decreases in the percentage of cold nights/days.

Very few studies of extreme temperature analysis have been done in India. Kothawale (2005) studied the temperature extremes in India by using the data of 40 stations well distributed over India for the period 1970-2002, and noted that heat wave conditions are relatively more frequent in May than in June, while very few heat waves occurred in the months of March and April. He also noted that the number of hot days is maximum over central part of India and minimum along the west coast of India during the pre-monsoon season. Recently, Rao et al (2005) studied trends in the frequency of occurrence of extreme temperatures over India during the pre-monsoon and winter seasons, using daily data at 103 stations for the period 1971-2000. They reported that, in Peninsular India during MarchMay, $80 \%$ of stations showed an increasing trend in the days with critical extreme maximum and minimum temperatures. In the northern part of India, $40 \%$ stations showed increasing trend in the days with critical extreme maximum temperature while about $80 \%$ of the stations showed increasing trend in the extremes in night temperatures.

In India, pre-monsoon is the warmest season of the year, also referred to as the hot-weather season, and anomalously high daily temperatures during this season severely affect human health and comfort. Identification of long-term changes in such conditions and their spatial extents is of critical importance to the development of appropriate risk management strategies. In view of this, the present paper examines the trends in the frequency of occurrence of temperature extremes in maximum and minimum temperatures and day-to-day fluctuations (intra-seasonal variability) of daily temperatures during the pre-monsoon season.

\section{Data and analysis}

\subsection{Data}

The daily maximum and minimum temperatures data of 121 stations well distributed over the country (figure 1) have been used in the present study, covering the period 1970-2005. The basic sources of these data are the Indian Daily Weather Reports (IDWRs) and National Data Center of the India Meteorological Department (IMD).

In the present study, adequate care has been taken regarding the homogeneity of the data. The possible inhomogeneities in the data were first assessed by visual examination of the plots of the annual mean maximum and minimum temperature series at each station. Very few stations showed strong discontinuities in the series, and were promptly deleted from further analysis. The $\mathrm{RH}$ test (http://cccma.seos.uvic.ca/ETCCDMI/) is also used to examine the homogeneity of the data, however, inhomogeneity was not found in 


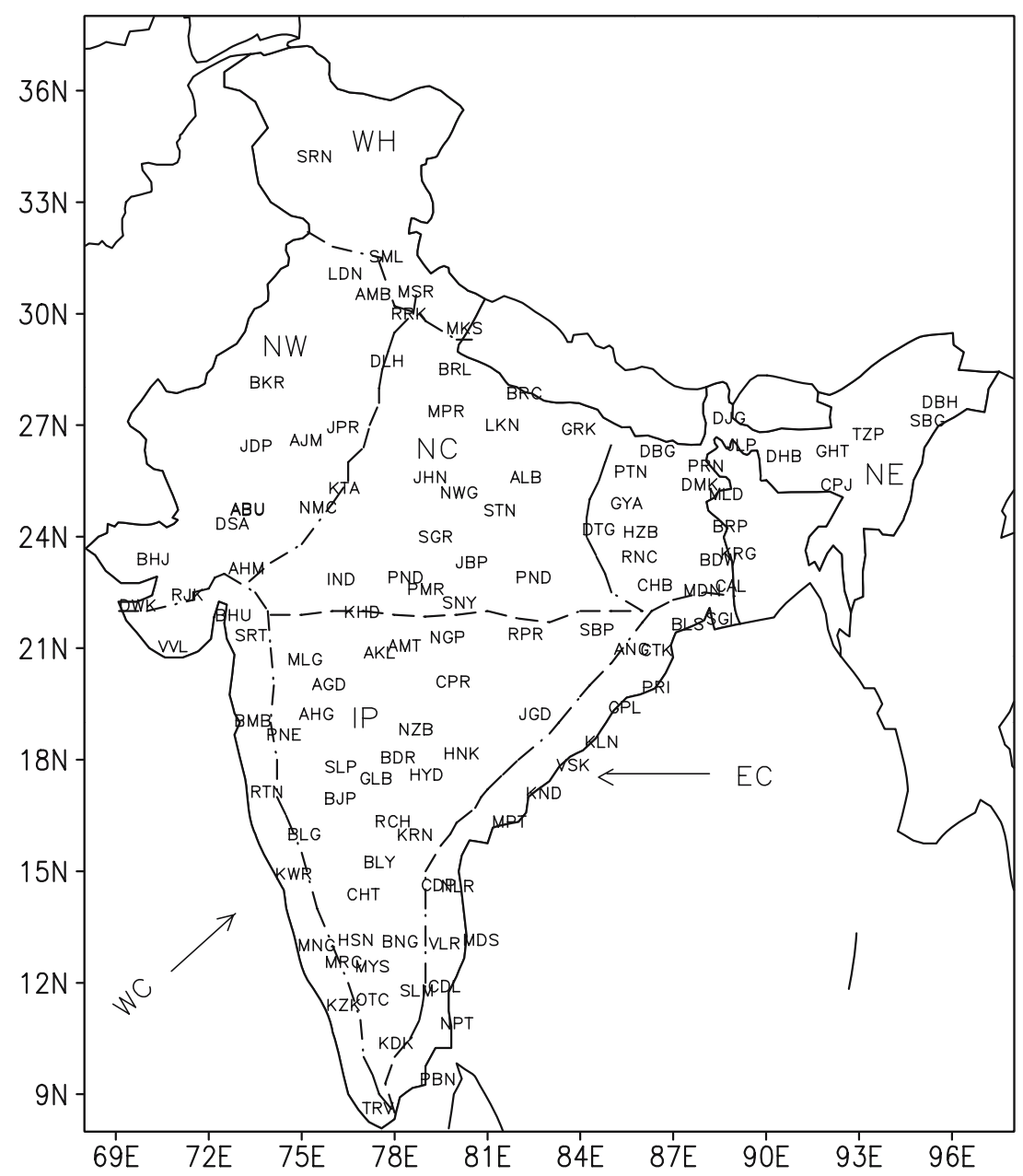

Figure 1. Network of 121 stations and homogeneous regions used in the study.

any station. Further quality control measures were also taken up to identify errors in data archival processes, such as keying or printing errors. The following procedures were followed to identify errors/outliers in the data series:

- Both maximum and minimum temperature are considered to be missing if daily maximum temperature is reported less than daily minimum temperature.

- On any given day, if the temperature differs by $\pm 10^{\circ} \mathrm{C}$ or more from the previous day as well as the next day, then the value is flagged as a potential outlier (Kothawale 2005). Whether the value can be really treated as an outlier or not was then determined by examining the weather situation on that day, and if there is no supporting evidence to the anomaly, it is treated as missing value.

- All the daily temperature values for individual stations/months that differ from their corresponding long-term means by more than four times their standard deviation were listed (Alexander et al 2006) and manually examined and compared with the anomalies at neighbouring stations, to determine whether they can be considered as outliers. Such identified outliers were also flagged as missing values.

In the daily temperature datasets, the proportion of missing values (actually missing in the datasets as well as outliers treated as missing) at individual stations ranges from 0 to $5 \%$ during the period 1970-2005. These missing values in the datasets have been filled by using appropriate methods as indicated below:

- If the daily temperatures were nearly uniform for 3 to 4 days before and after a given day with missing temperature data, the weather situation on that missing date is also normal, then the missing value was filled by the arithmetic average of the temperatures on the preceding and the following days of the missing date.

- Other missing daily temperature values have been objectively interpolated by using an inverse squared distance weighted average algorithm. In this method, daily temperature anomaly (from 
long term daily mean) series were prepared for all the stations. To interpolate the missing daily temperature, five nearest stations with reference to station with the missing value were selected within $2^{\circ}$ search radius, and the distance of each of the five stations from the reference station was computed. The procedures of this algorithm are given by Kothawale and Rupa Kumar (2002 and $2005)$. The total number of such interpolated values is less than $5 \%$ of the total number of data points.

\subsection{Data analysis}

Extreme temperature indices can be defined in several ways; using arbitrary thresholds (Jones et al 1999; Klein Tank and Konnen 2003) or by using percentile method (Plummer et al 1999; Alexander et al 2006). The arbitrary threshold values are generally used where the climate is less variable. However, India is a large country spanning a wide range of climates and there is no single temperature value that can be considered extreme in all regions (Pant and Rupa Kumar 1997; Kothawale 2005). Hence, in this study, extreme temperature indices are worked out based on the 10th and 90th percentiles. The 10th and 90th percentile values of daily temperatures based on the period 1970-2005 have been computed for each month and each station. Using these percentile values (extreme temperature indices), the number of hot and cold days in daily maximum temperature and number of hot and cold nights in daily minimum temperature were identified for the months March through May for entire data period. The hot/cold days as well as hot/cold nights are used to estimate the frequencies of extreme temperature events. The monthly frequencies of extreme temperature events have been seasonally cumulated over to obtain the time series of pre-monsoon seasonal frequencies of the extremes. More specifically, the extreme temperature events are identified as follows:

- Hot days = Days with maximum temperatures above 90th percentile

- Cold days = Days with maximum temperatures below 10th percentile

- Hot nights = Nights with minimum temperatures above 90th percentile

- Cold nights = Nights with minimum temperatures below 10th percentile

Regionally averaged series of the seasonal frequencies of extreme temperature events have been constructed for the country as a whole (all-India) and also for seven homogeneous regions viz., Western Himalaya (WH), Northwest (NW), Northeast (NE), North Central (NC), East coast (EC),
West coast (WC) and Interior Peninsular (IP) by taking the arithmetic average of the frequencies at the stations falling within the respective regions. These homogeneous regions are subjectively demarcated based on uniform geographical, topographical and climatological features (Hingane et al 1985; Kothawale and Rupa Kumar 2005). Similar approach to prepare regional series of extremes was also adopted by Goswami et al (2006), who prepared extreme rainfall frequency series for the monsoon season over central India. The different time series representing the variation of extreme temperature events during the data period prepared as above have been examined for long term trend. The trend is quantified by the slope of a simple linear regression line fitted to each of the series against time and expressed as trend per ten year. The statistical significance of trend is assessed by means of Mann Kendall rank statistics.

\section{Daily maximum and minimum temperature variations over India}

\subsection{Annual cycle}

In order to understand the nature of extreme temperature events, it is important to consider the characteristics of the mean annual cycle of temperature on a daily scale. The mean annual cycles of all-India mean daily maximum and minimum temperatures are depicted in figure 2. These annual cycles are represented by mean of all-India daily temperatures over the period 1970-2005. The temperature increases from January and attains a peak in the month of May, later they start to decrease up to December. During the pre-monsoon (March + April + May) season, the Indian region is marked by clear skies, which, coupled with intense as well as increased solar radiation, result in high temperatures. Particularly in the month of May the occurrence of heat wave conditions is more frequent than in June. While very few heat waves occur in the months of March and April (Kothawale 2005).

\subsection{Trends in frequency of occurrence of extreme pre-monsoon temperatures}

\subsubsection{Maximum temperatures}

In this section, the trends in frequencies of temperature extremes during the pre-monsoon season have been examined for India as a whole and the homogeneous regions (figure 3) as well as trend at station level (figure 5). For India as a whole, frequency of hot days shows a gradual increasing 


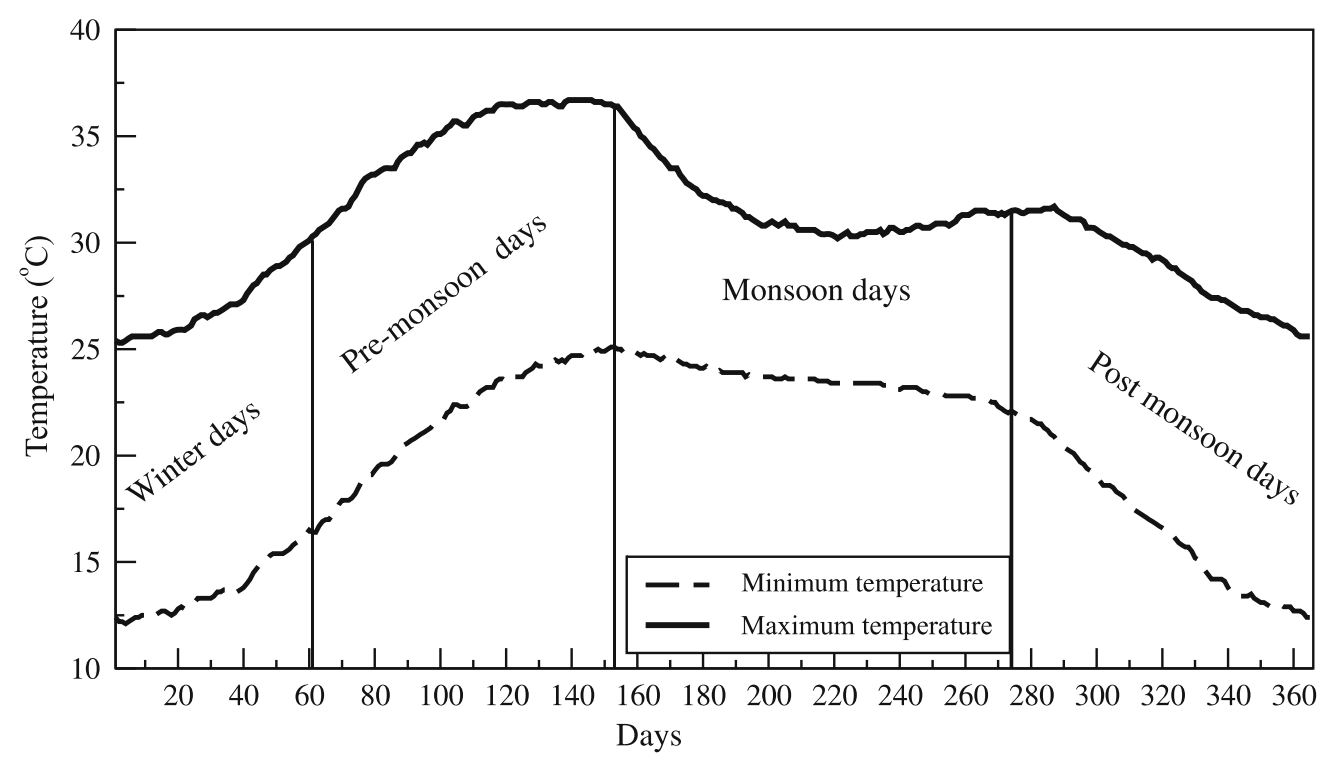

Figure 2. Annual cycle of All-India daily maximum and minimum temperatures.

trend and frequency of cold days shows significant decreasing trend during the pre-monsoon season over the period 1970-2005. On the regional scale, the trends in the frequency of occurrence of temperature extremes are slightly different. The homogeneous regions of EC, WC and IP show a significant increasing trend in frequency of hot days. The regions in the northern part of India (north of $22^{\circ} \mathrm{N}$ ) do not show significant increasing or decreasing trend in the extreme temperature events. Nearly $70 \%$ of the stations falling in these regions showed decreasing trend and remaining 30\% showed increasing trend. While, few stations in NE India showed significant decreasing trend (figure 5).

All-India and all homogeneous regions showed decreasing trend in frequency of cold days. Out of seven homogeneous regions only two regions namely $\mathrm{WH}$ and $\mathrm{WC}$ showed significant decreasing trend of 2.1 and 2.7 days per decade respectively. Kothawale and Rupa Kumar (2005) reported earlier that over these two regions (WH and WC), premonsoon maximum temperatures have increased significantly. The significant decreasing trend in cold days over these two regions may be a manifestation of the increasing trend in seasonal maximum temperatures. Further, Kripalani et al (2003) have reported that the spring snow cover of Western Himalaya has been declining and that the snow was melting faster from winter to spring after 1993, which is consistent with the trends observed in the present study.

To summarize, the frequency of hot days has been increasing almost all over the regions, significantly over EC, WC, and IP India and decreasing over NE. On the other hand, the number of cold days has been decreasing over all the regions with significant trends over $\mathrm{WH}$ and $\mathrm{WC}$ regions of India. In more detail, over the entire country, majority of stations showed decreasing trend (including significant and not significant), while very few stations (4 to 5) showed significant increasing trend (figure 5b). For India as a whole, the significant decreasing trend in the frequency of cold days and increasing trend (close to 5\% significant level) in frequency of hot days have been found.

\subsubsection{Minimum temperatures}

The trends in frequency of hot nights and cold nights, based on the extremes in daily minimum temperatures, are shown in figures 4 and 5. Significant increasing trend in the frequency of hot nights is observed over NW, EC and WC India as well as for India as a whole. It is important to note that in the case of EC and WC regions the trends in the frequency of hot days as well as hot nights are significant. The above-mentioned three regions, where significant increasing trends in hot nights are found, also showed significant warming trend on seasonal scale in pre-monsoon mean minimum temperatures for the period 1971-2003 (Kothawale and Rupa Kumar 2005). Thus, the increasing trend in the occurrence of hot nights is also reflected in the warming trend in mean monthly as well as seasonal minimum temperatures.

The frequency of cold nights has decreased over almost all the homogeneous regions during the period 1970-2005 (figure 4). For India as a whole, the frequency of cold nights decreased at the rate of 0.9 days per decade, the trend is close to 

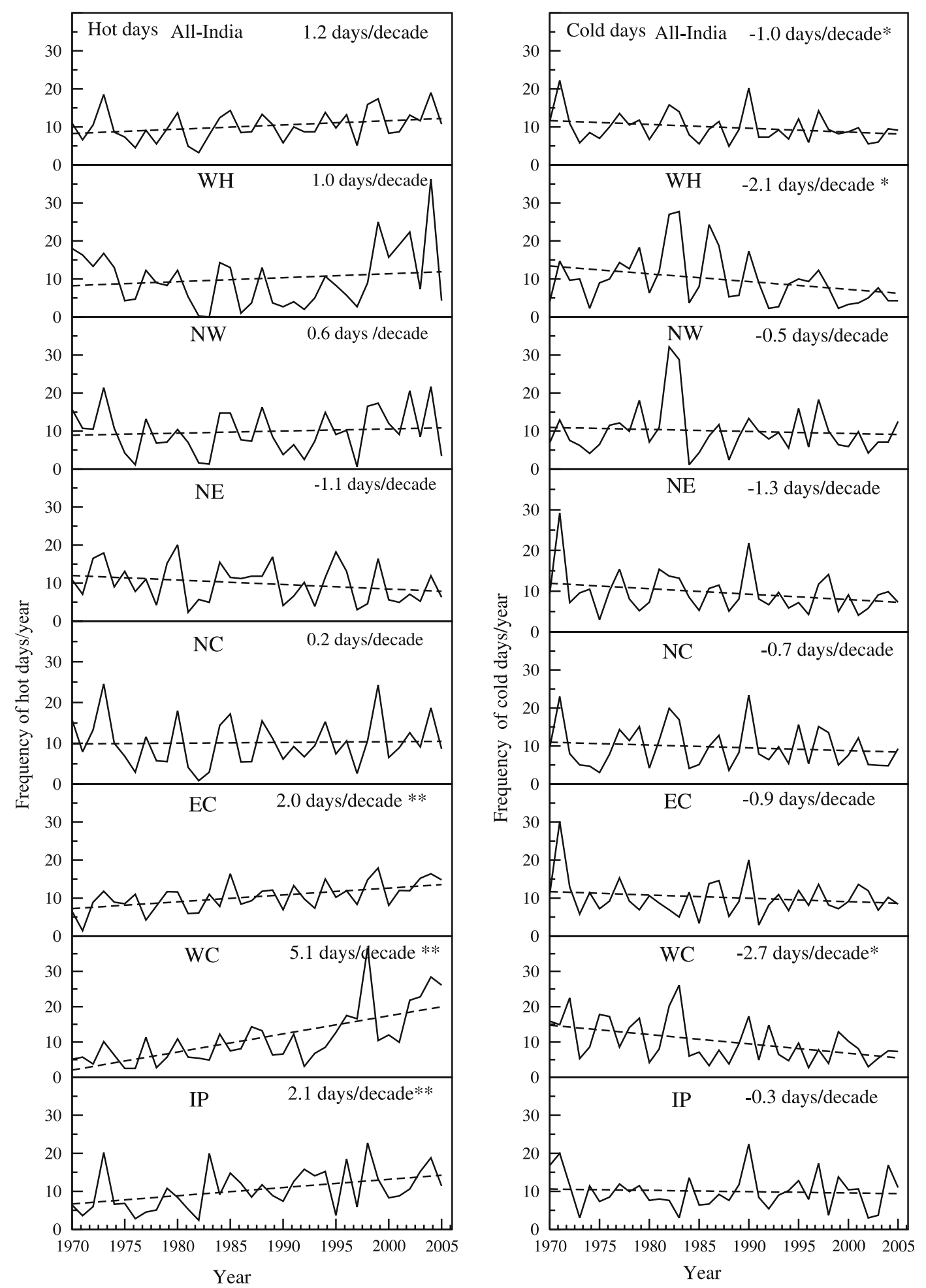

Figure 3. Frequency of hot and cold days during pre-monsoon season over different homogeneous regions: 1970-2005 (* significant at $5 \% ; * *$ significant at $1 \%$ ).

$5 \%$ significant level. Out of the seven homogeneous regions, the statistically significant decreasing trend in frequency of cold nights was found over WH and NE. In summary, it can be stated that the hot nights have increased and cold nights have decreased almost over the entire country.

\subsubsection{Trends in mean seasonal maximum and minimum temperatures and frequency of extreme temperature events}

Statistically significant increasing trend in the frequency of hot days and nights as well as decreasing 

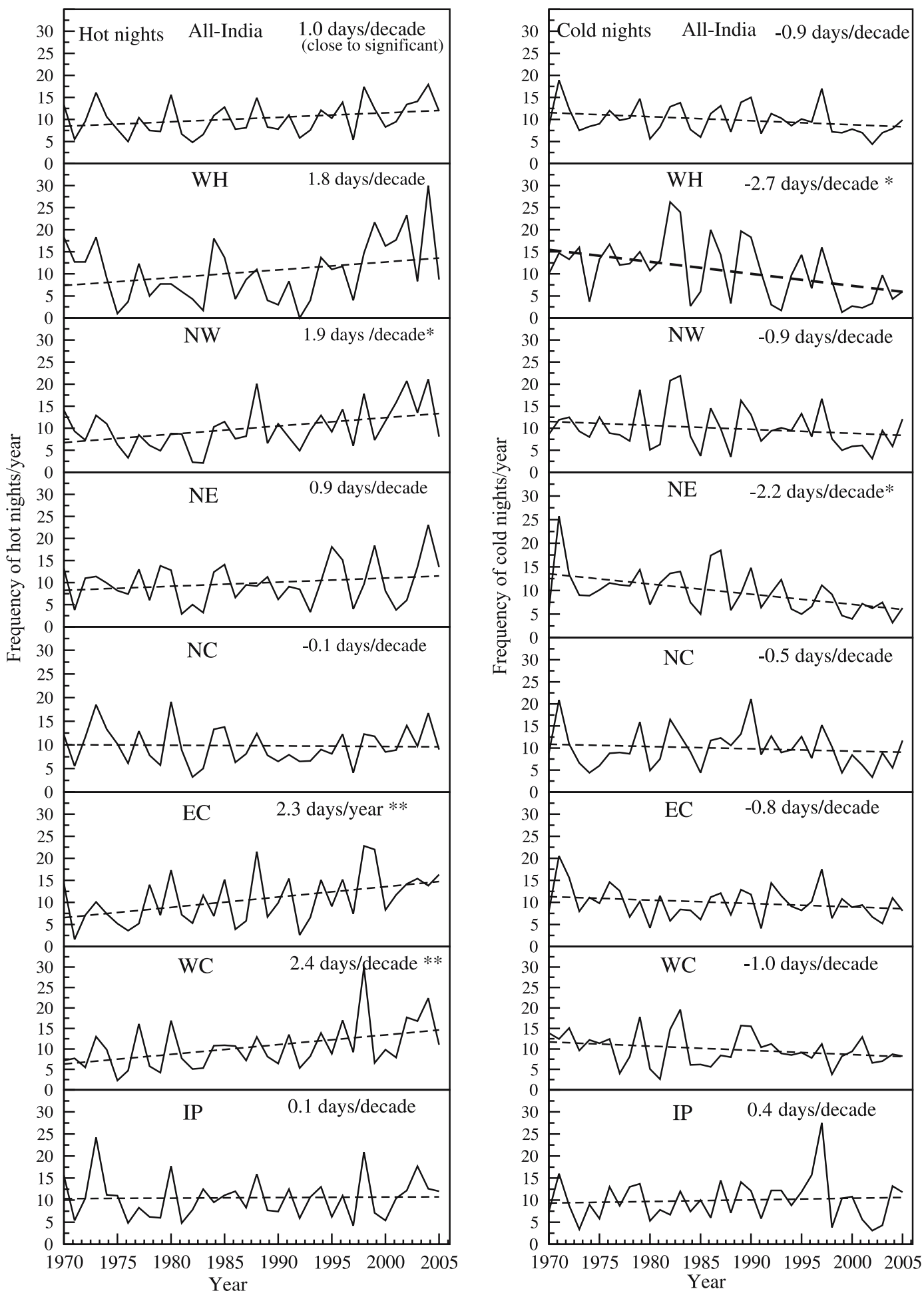

Figure 4. Frequency hot and cold nights during pre-monsoon season over different homogeneous regions: 1970-2005 (* significant at $5 \% ; * *$ significant at $1 \%)$.

trend in the frequency of cold days and nights are observed over some particular regions is reported in previous section. Kothawale and Rupa Kumar (2005) have also mentioned that the pre-monsoon mean maximum temperatures have increased over major part of India during 1971-2003. Present study is undertaken to investigate whether the trends in extreme temperature events are the manifestation of trends in seasonal temperatures. In view of this, extreme events in daily temperatures are identified after removing trend from it at each station for the months March through May 
Trend in frequency of hot days

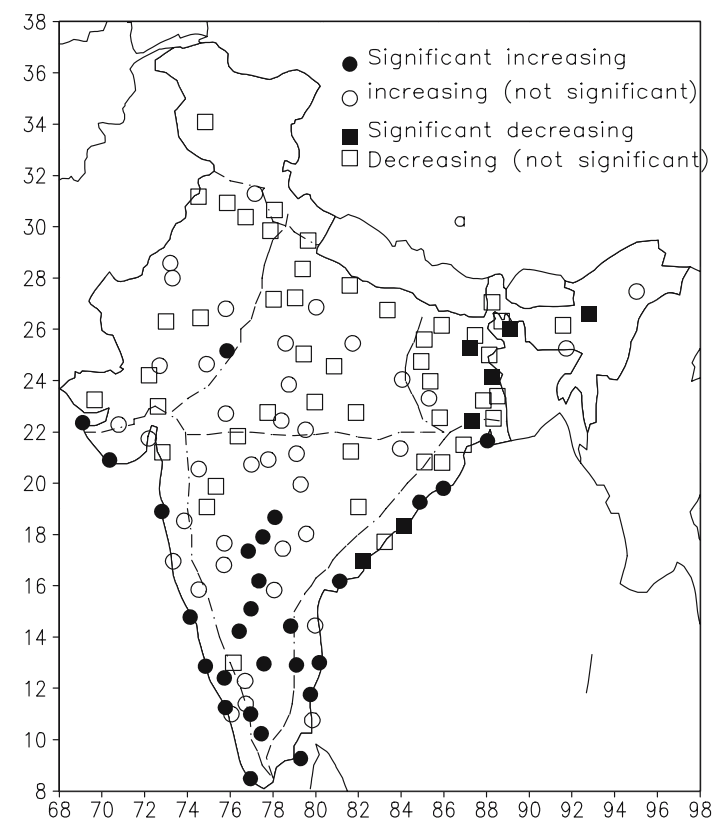

Trend in frequency of hot nights

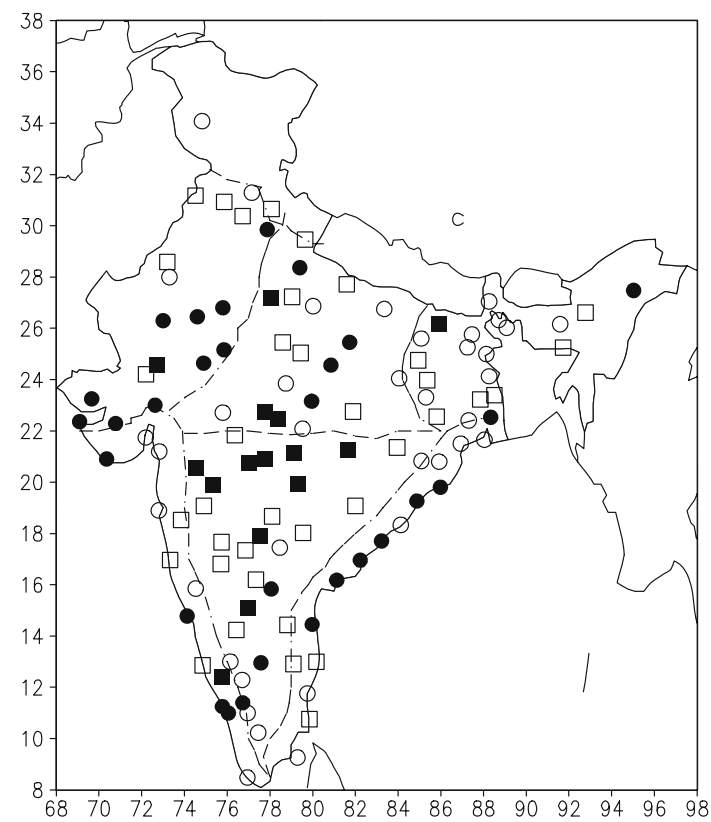

Trend in frequency of cold days

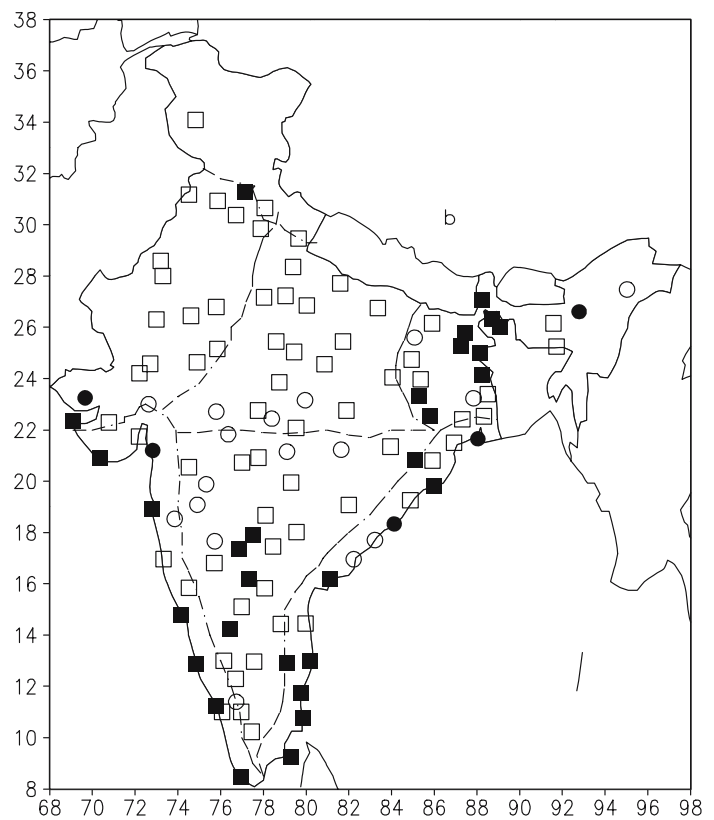

Trend in frequency of cold nights

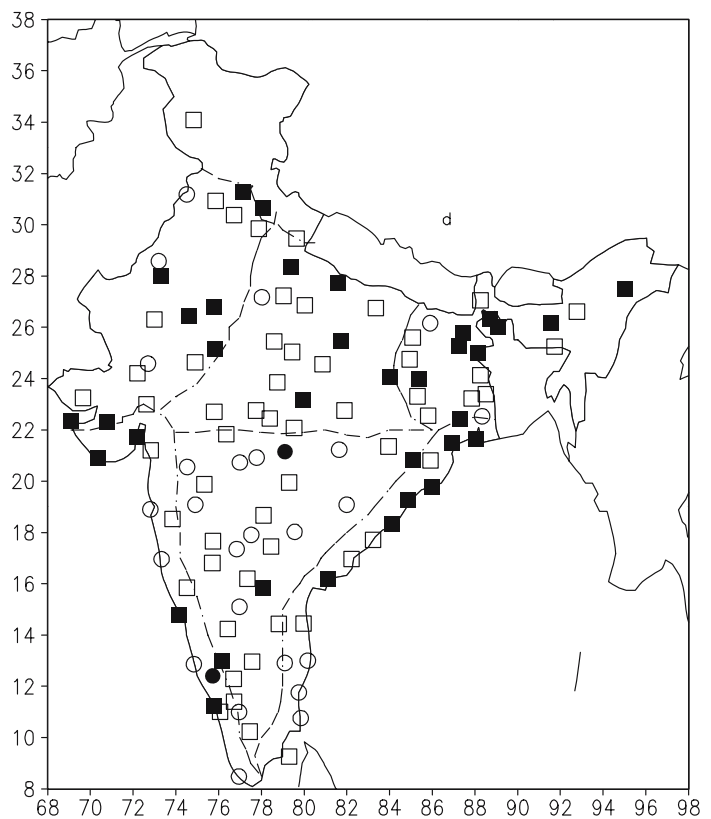

Figure 5. Trends in frequency of extreme temperature events of each stations in different homogeneous regions of India for the period 1970-2005.

for the period 1970-2005 and prepared the regional series of frequency of extreme events. Further, the trends in mean seasonal maximum and minimum temperatures of homogeneous regions as well as regional frequency of extreme events are computed and shown in table 1.

Table 1 shows that the mean seasonal maximum temperature has significantly increased over two regions namely $\mathrm{EC}$ and $\mathrm{WC}$ India during the period 1970-2005 and these two regions also showed significant increasing trend in frequency of hot days, before removing trend from daily temperatures. The seasonal mean minimum temperature has significantly increased over $\mathrm{WH}, \mathrm{NE}, \mathrm{EC}$ and WC India. However, only two regions WC and EC showed significant increasing trend in the frequency of hot nights and $\mathrm{WH}$ and $\mathrm{NE}$ showed only increasing tendency (not significant trend). 


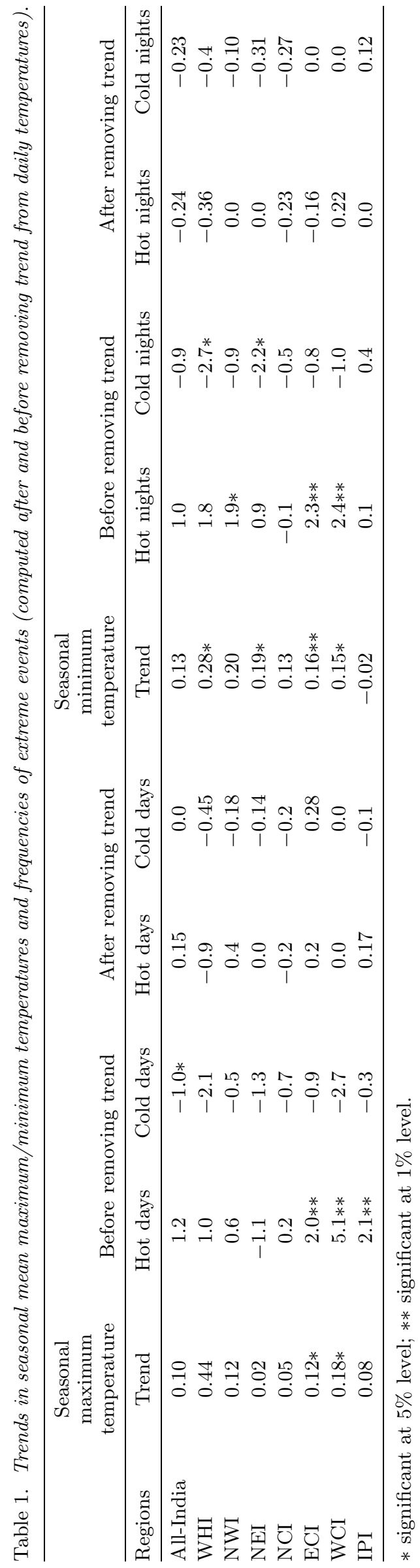

There is no significant increasing or decreasing trend in the frequency of extreme events, when they are computed from daily detrended temperature data. The time series of extreme events, where trend is statistically significant, are depicted in figure 6 before and after removing trend from the daily data. From the analysis it is clear that the increase in hot days and nights and decrease in cold days and nights are consistent with the increasing trend in monthly/seasonal maximum and minimum temperatures, respectively. Thus, there is a high likelihood of seasonal-scale warming to be associated with a marked increase in the frequency of extreme hot-weather events.

\section{Trends in extreme temperatures}

The trends in the frequency of occurrence of extreme events discussed above do not provide information on the intensity of the extremes. In this section, an attempt has been made to bring out the trends in the magnitudes of extreme temperatures on regional scale as well as India as a whole. For extreme temperature trend analysis, the pre-monsoon (total days 92) daily temperature series was prepared for each station for the period 1970-2005. From these stations daily temperature series, the 90th and 10th percentiles of daily maximum and minimum temperatures were identified for each pre-monsoon season, representing the corresponding extremes. Since, the premonsoon season comprises of 92 days and its 10th and 90th percentile values are 9 th and 81 th respectively, while data is arranged in ascending order. The average extreme temperature is calculated for each season and each station by averaging values exceeding the percentile limit in that season. This averaged daily temperature represents the 90/10th percentile (extreme) temperature of that respective year. The homogeneous regions extreme temperature series were constructed by taking the arithmetic average of station extreme temperatures of the respective region.

Figure 7 shows the time series of all-India and homogeneous regions mean daily temperature of the 90th and 10th percentile of maximum temperatures. All-India as one unit, the 90th percentile of daily maximum temperature, hereafter referred to as warm day temperature, gradually increases over the period 1970-2005, however, trend is not statistically significant. The 10th percentile of maximum temperature, hereafter referred to as cool day temperature, shows significant increasing trend at $5 \%$ significant level. Kothawale and Rupa Kumar (2005) reported an accelerated warming of $0.20^{\circ} \mathrm{C}$ in the mean annual maximum temperatures during the recent three decades (1971-2003), which 

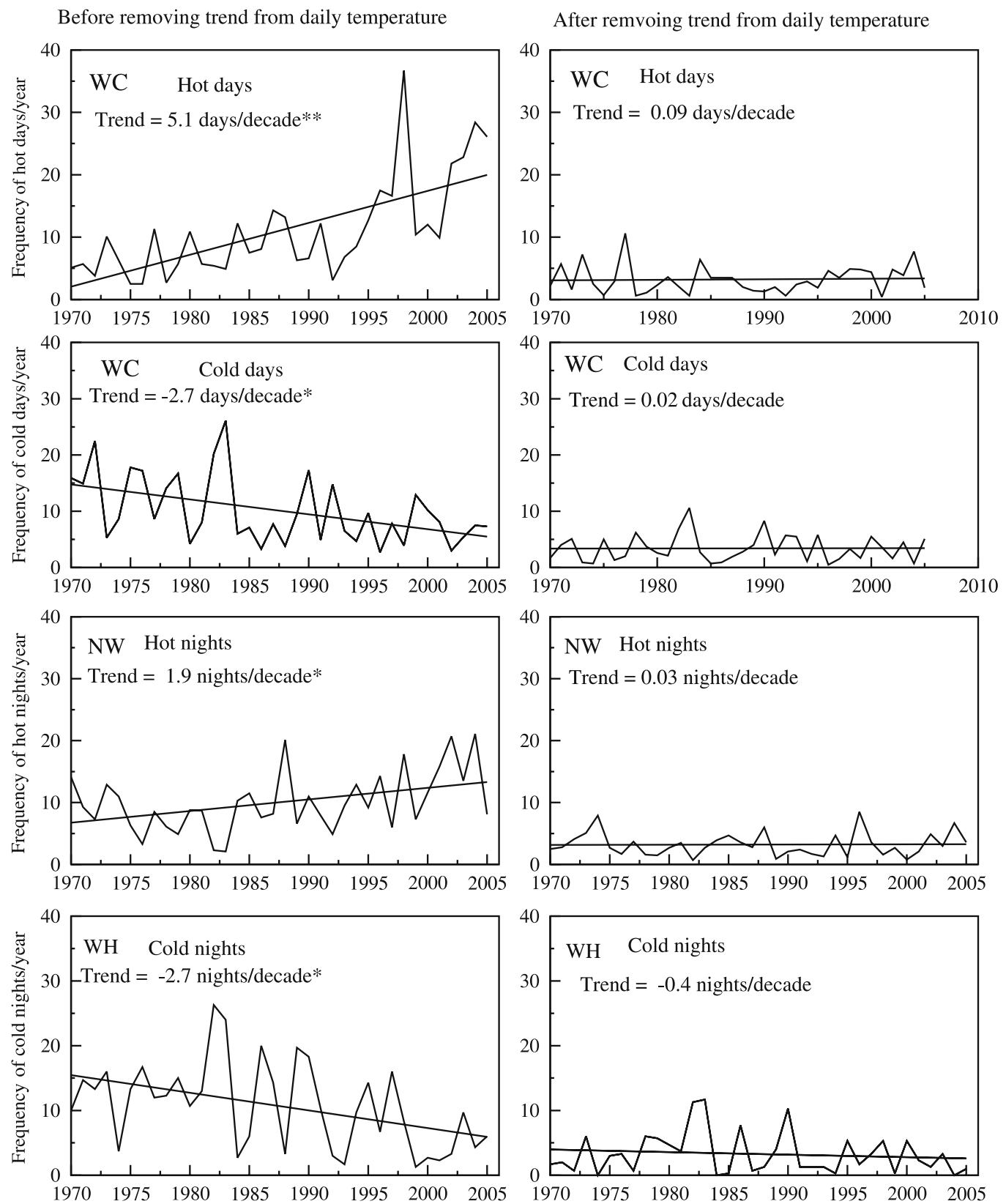

Figure 6. Trends in frequency of extreme temperature events, before and after removing trend from daily temperature data (* significant at 5\%; ** significant at $1 \%$ ).

they showed to be largely due to an unprecedented warming in the last decade. On the regional scale, the warm day temperatures have significantly increased over the southern regions of WC and IP, the increase in temperature is monotonous while the northern parts of India do not show any significant trend, however, temperature is more fluctuating around the mean. In the case of cool day temperatures, $\mathrm{WH}$ and $\mathrm{WC}$ regions show significant positive trend. It is to be noted that WC warm as well as cool day temperatures show significant warming trend.

Figure 8 shows the time series of all-India and homogeneous regions mean daily temperature of the 90th and 10th percentiles of minimum temperatures. For all-India, the 90th and 10th percentiles of daily minimum temperatures (hereafter referred to as warm night temperature and cool night temperature, respectively) are increasing, however only cool night temperature shows significant increasing trend. On the other hand, warm nights do not show significant increasing trend over any region while cool night temperatures show significant increasing trend over $\mathrm{WH}, \mathrm{NW}$ and $\mathrm{WC}$ regions.

To summarize, the trends in the frequency of extreme events such as hot days and nights as well as those in the warm days and nights of daily maximum and minimum temperatures indicate 

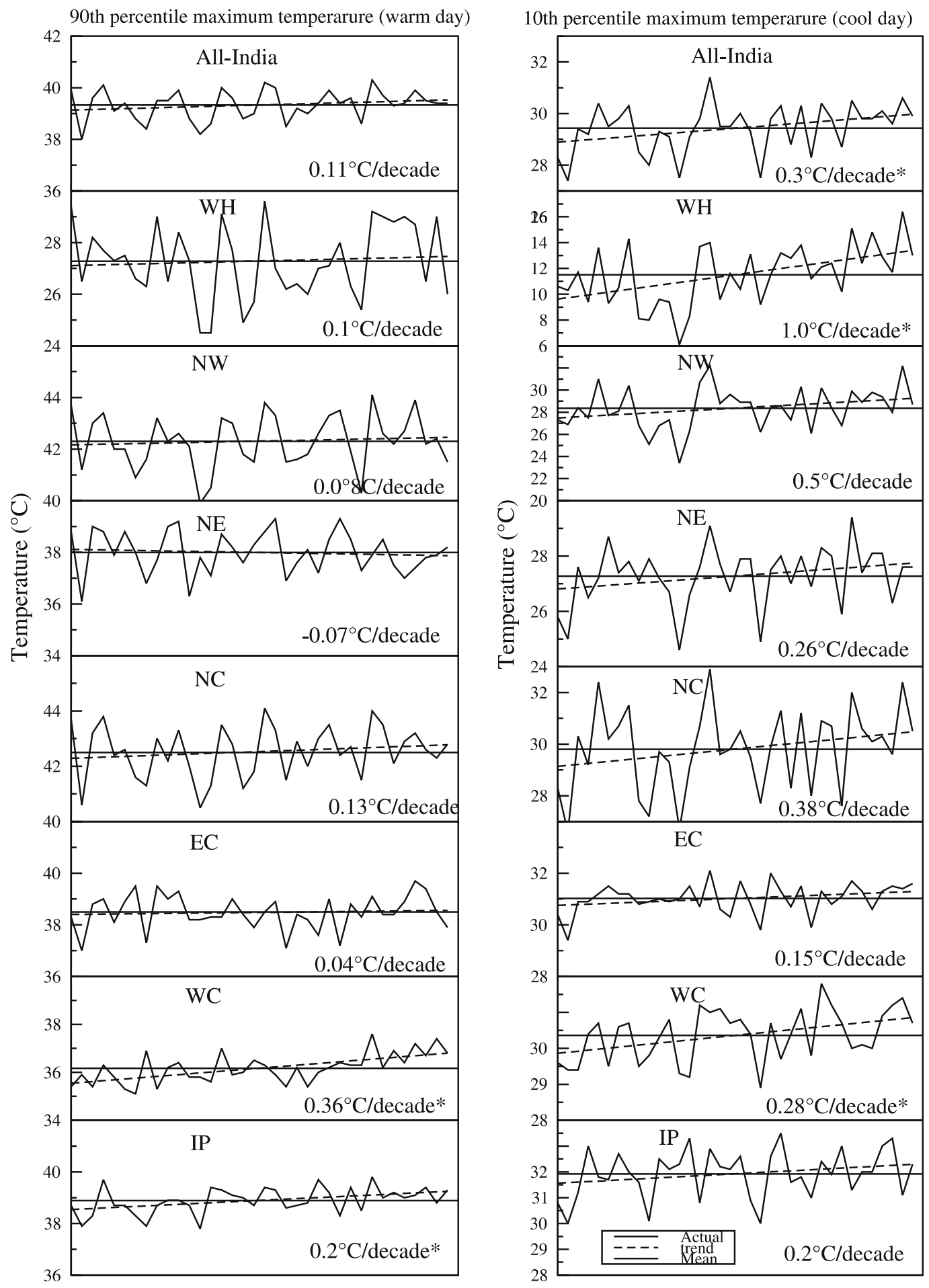

Figure 7. The 90th and 10th percentiles of daily maximum temperatures (warm and cool) during pre-monsoon season for the period $1970-2005$ (* significant at 5\% level).

that significant increases in the frequency of extreme temperature events are also associated with significant increases in the magnitudes of the extreme temperatures. While for most of the regions, significant decrease in frequency of cold days and nights associated with significant increase in cool day and night temperatures.

\section{Day-to-day fluctuations (intra- seasonal variability) of daily maximum and minimum temperatures}

Significant changes in the frequency as well as magnitudes of extreme temperature events have been found over some regions, as described in the 

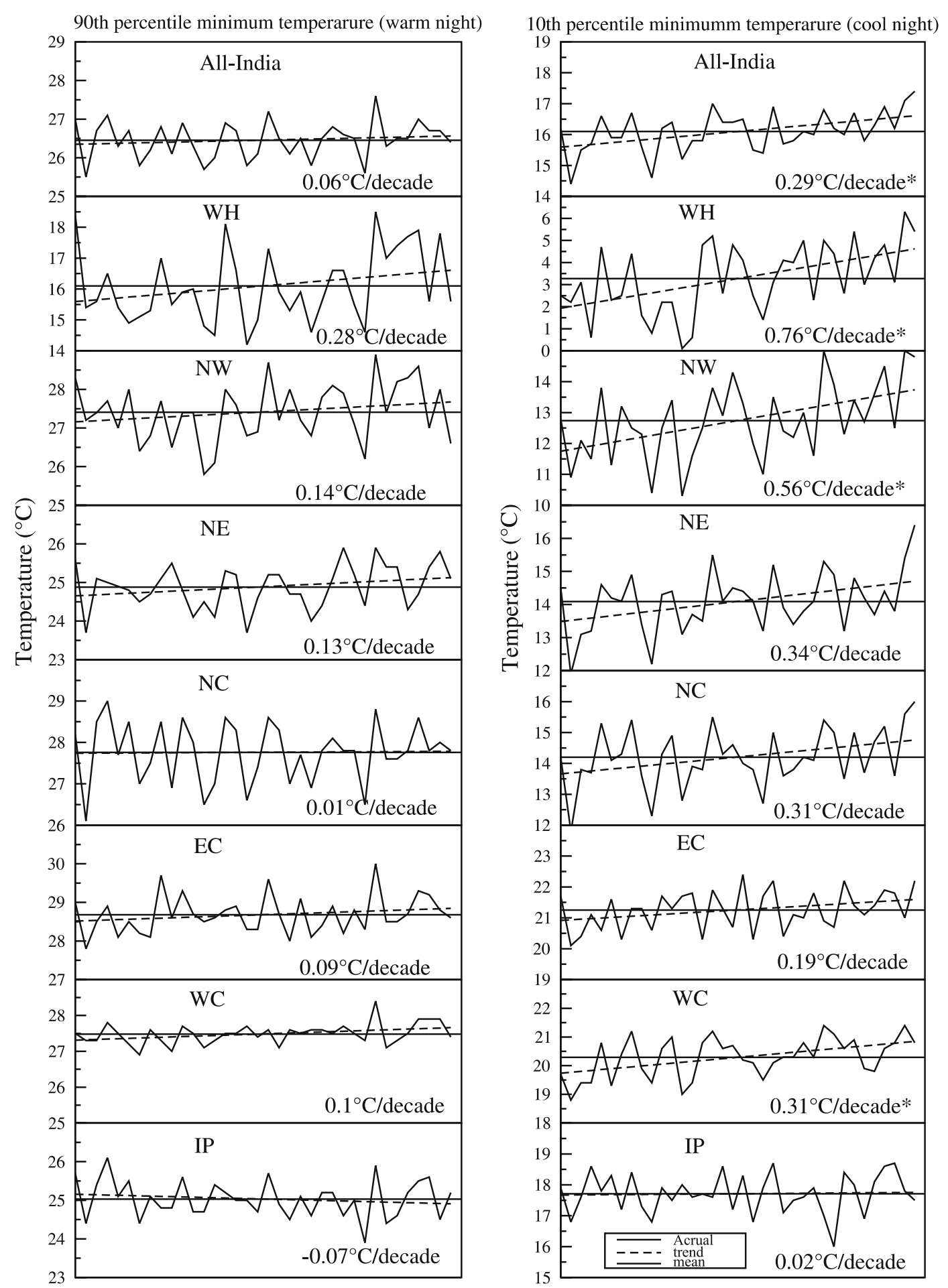

Figure 8. The 90th and 10th percentiles of daily minimum temperatures (warm and cool night) during pre-monsoon season for the period $1970-2005$ (* significant at 5\% level).

earlier sections. In conjunction with this, it was important to examine whether the levels of dayto-day fluctuations in the temperatures have also changed. For this purpose, trends in standard deviation of daily maximum and minimum temperatures within the pre-monsoon season have been examined on regional scale. For this trend analysis, regional standard deviation series have been prepared by taking arithmetic average of the standard deviations at the respective stations. Gong and Chang (2004) have also similarly prepared regional mean variance series for East Asia by averaging variance of all the stations in the respective regions. 

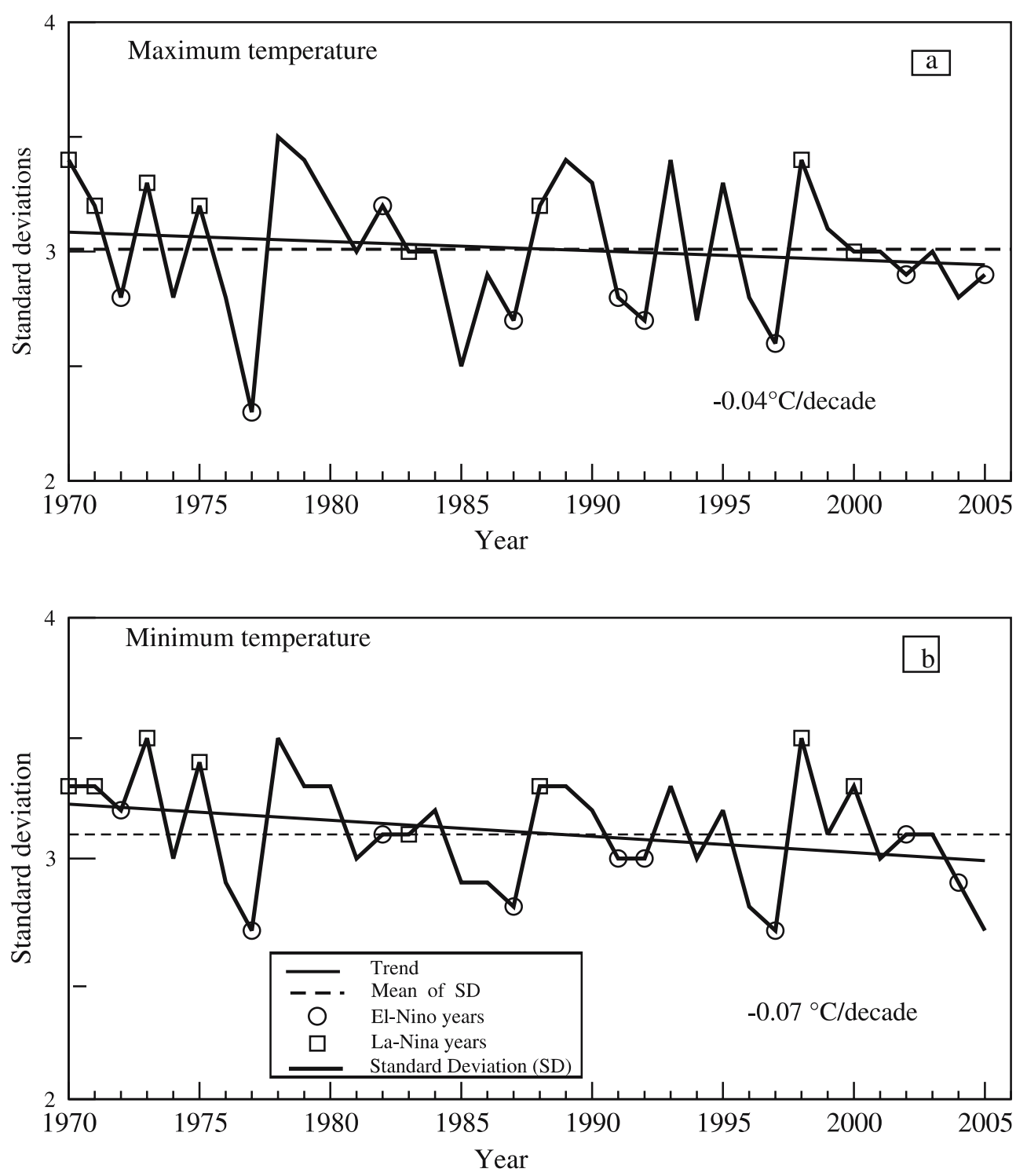

Figure 9. (a, b) Day-to-day fluctuations (intra-seasonal variability) of maximum and minimum temperatures during premonsoon season over India.

Prior to this analysis, the daily temperature anomalies of each station and each season were computed by removing their annual cycle. In this way influence of seasonal cycle of air temperature was removed. Similar approach has been adopted by Rajmund Przyblak (2002) and Gong and Chang (2004) to compute intra-seasonal variability of daily maximum and minimum temperatures of different regions. The annual cycle in the present case is represented by the simple average of daily temperatures for each of the 365 days over the period 1970-2005 smoothened by 5-point running means to damp the few strong fluctuations. By using the station-wise daily temperature anomalies, the standard deviations of each pre-monsoon season have been calculated for every year over the entire period 1970-2005. The regional standard deviation series were then prepared by computing the arithmetic average of the standard deviations of temperatures at stations in the respective regions.

Figure $9(a, b)$ shows the variations of the level of day-to-day fluctuations of maximum and minimum temperatures within the pre-monsoon season, for India as a whole. The time series of mean standard deviation (SD) within the pre-monsoon season of daily maximum temperature do not show any significant trend. The SD values are fluctuating within $\pm 0.5^{\circ} \mathrm{C}$. On the regional scale (not shown), none of the regions exhibited significant trend except $\mathrm{WH}$, where the SD is significantly decreasing by $0.27^{\circ} \mathrm{C}$ per decade.

The trends in the level of day-to-day fluctuations of minimum temperatures are similar to those of maximum temperatures. All-India SD time series 
shows slight negative trend, but it is not significant (figure 9b).

The SD time series of both maximum and minimum temperatures also show the magnitudes of the fluctuations were anomalous in certain years during the 1970s and the 1990s. To further examine these aspects, the yearly SD values (for pre-monsoon season) have also been checked for their possible association with the occurrence of El-Niño and La-Niña events whose significant influence over the Indian climate is well-known (Pant and Rupa Kumar 1997). Halpert and Ropelewski (1992) have also examined the association of global and large scale regional temperature patterns with the Southern Oscillation and reported that the ENSO influences the surface temperatures on regional and global spatial scale. Figure 9(a, b) shows that during El-Niño years, the SD of pre-monsoon daily temperatures is below normal, while during the La-Niña years it is above normal. The day-to-day variability $(\mathrm{SD})$ is generally weaker during El-Niño years and vice versa in La-Niña years.

On the whole, there is no significant change in the level of the day-to-day fluctuations of pre-monsoon daily maximum and minimum temperatures. The slight tendency towards subdued fluctuations of daily temperature anomaly of maximum and minimum temperatures could be the result of increasing trend in frequency of occurrence of hot days and nights and decreasing trend in cold days and nights.

\section{Conclusions}

- During the pre-monsoon season, for India as a whole, the frequency of hot days and nights has increased, however, statistically significant trend is observed for hot nights. The frequency of cold days and nights has decreased over the period 1970-2005, the trend in frequency of cold days is significant at $5 \%$ level.

- On a regional scale, frequency of hot days has significantly increased over the southern parts of India, but there is no significant change over the northern parts of India.

- Hot nights have increased over all the regions, with significant increase over NW, EC and WC India, whereas cold nights have decreased over all the regions with significant decrease over WH and NE.

- The increase in frequency of hot days and nights and decrease in cold days and nights are consistent with the increasing trend in monthly/seasonal maximum and minimum temperatures, respectively.

- In general, trends in the frequency of the occurrence of extreme events as well as trends in 90th and 10th percentiles of both daily maximum and minimum temperatures indicate that the increase in the frequency of hot weather events during the pre-monsoon season has also been associated with an increase in their intensity.

- Examination of changes in the day-to-day fluctuations in the temperatures indicates that the daily maximum and minimum temperatures are becoming less variable during the recent decades.

\section{Acknowledgements}

The authors are thankful to Prof. B N Goswami, Director, Indian Institute of Tropical Meteorology (IITM), Pune for providing the necessary facilities for this study, and Dr N Singh, Head, Climatology \& Hydrometeorology Division, IITM. The authors are also grateful to National Data Center of India Meteorological Department for providing the basic temperature data.

\section{References}

Alexander L V et al 2006 Global observed changes in daily climate extremes of temperature and precipitation; J. Geophys. Res. 111 D05109, doi:10.1029/ 2005JD006290.

Arthur T D and Allan R J 2002 Trends in twentieth century temperature extremes across the United States; J. Climate 15 3188-3205.

Easterling D R, Evans J L, Grosmam P Y, Karl T R, Kunkel K E and Ambenje P 2000 Observed variability and trends in extreme climate events: Brief review; Bull. Amer. Meteor. Soc. 81 417-425.

Gong D Y and Chang H H 2004 Intra-seasonal variability of winter temperature over East-Asia; Int. J. Climatol. 24 131-144.

Goswami B N, Venugopal V, Sengupta D, Madhusoodan M S and Xavier P K 2006 Increasing trend of extreme rain events over India in a warming environment; Science 314 1442, doi 10.1126/science.1132027.

Hingane L S, Rupa Kumar K and Ramana Murthy Bh V 1985 Long-term trends of surface air temperature in India; Int. J. Climatol. 5 521-528.

Halpert M S and Ropelewski C F 1992 Surface temperature patterns associated with the Southern Oscillation; J. Climate 5 577-593.

Houghton J T, Ding Y H, Griggs D J, Noguer M, van der Linden P J, Dai X, Maskell K and Johson C A (eds) 2001 The Scientific Basis. Contribution of Working Group I to the Third Assessment Report of the Intergovernmental Panel on Climate Change (Cambridge: Cambridge University Press).

Hyun S J, Choi Y and Gyu-Holim J 2002 Recent trends in temperature and precipitation over South Korea; Int. J. Climatol. 22 1327-1337.

Jones P D, Horton E B, Folland C K, Hulme M, Parker D E and Basnett T A 1999 The use of indices to identify change in climatic extreme; Climate Change 42 131-149.

Jones P D and Moberg A 2003 Hemispheric and large scale surface air temperature variations; An extensive revision and an update to 2001; J. Climate 16 206-223. 
Karl T R, Knight R W, Easterling D R and Quayle R G 1996 Indices of climate change for United States; Bull. Amer. Meteor. Soc. 77 279-292.

Klein Tank A M G and Konnen G P 2003 Trends in indices of daily temperature and precipitation extreme in Europe, 1946-1999; J. Climate 16 3665-3680.

Klein Tank A M G et al 2006 Changes in daily temperature and precipitation extremes in central and south Asia; J. Geophys. Res. 111 D16105, doi:10.1029/ 2005JD006316.

Kothawale D R 2005 Surface and upper air temperature variability over India and its influence on Indian monsoon rainfall; Ph.D Thesis, University of Pune, pp. 212.

Kothawale D R and Rupa Kumar K 2002 Tropospheric temperature variation over India and links with the Indian summer monsoon: 1971-2000; Mausam 53(3) 289-308.

Kothawale D R and Rupa Kumar K 2005 On the recent changes in surface temperature trends over India; Geophys. Res. Lett. 32 L18714, doi:10.1029/2005GL023528.
Kripalani R H, Kulkarni A and Sabade S S 2003 Western Himalaya snow cover and Indian monsoon rainfall: A re-examination with INSAT and NCEP/NCAR data; Theoretical Applied Climatology 74 1-18.

Manton M J et al 2001 Trends in extreme daily rainfall and temperature in Southeast Asia and South Pacific: 1961-1998; Int. J. Climatol. 21 269-284.

Pant G B and Rupa Kumar K 1997 Climates of South Asia (Chichester: John Wiley \& Sons) 320pp. (ISBN 0-47194948-5).

Plummer N, Salinger M J, Nicholls N, Suppich R, Hennessy K J, Leigthan R M, Treulin B C, Page C M and Lough J M 1999 Changes in climate extreme over the Australian region and New-Zealand during the twentieth century; Climate Change 42(1) 183-202.

Rajmund Przbylak 2002 Changes in seasonal and annual high frequency air temperature variability in the Arctic from 1951 to 1990; Int. J. Climatol. 22 1017-1032.

Rao G S P, Murthy M K and Joshi U R 2005 Climate change over India as revealed by critical extreme temperature analysis; Mausam 56 601-608. 